Check for updates

Cite this: RSC Adv., 2018, 8, 11930

Received 14th February 2018

Accepted 20th March 2018

DOI: $10.1039 / c 8 r a 01411 f$

rsc.li/rsc-advances

\section{Adsorption of tetrakis(4-sulfophenyl)porphyrin onto liposomal surfaces composed of neutral diacylphosphatidylcholine and release by cyclodextrin $\dagger$}

\author{
Yuki Tsuchiya, Toshimi Nakaya, Tomoyuki Kakigi, Kouta Sugikawa (D) \\ and Atsushi Ikeda (D) *
}

Anionic tetrakis(4-sulfophenyl)porphyrin (TPPS) interacts with liposomal surfaces composed of neutral diacylphosphatidylcholine at high lipid concentrations. TPPS interacted with liposomal surfaces through four contact points. The association constant was obtained to be $9.0 \times 10^{5} \mathrm{M}^{-4}$. TPPS was peeled off the liposomal surfaces by the addition of cyclodextrin.

\section{Introduction}

The adsorption of compounds such as polymers and nanoparticles onto the cell surface is important in developing drug carriers $^{1-5}$ and functional materials. ${ }^{6-12}$ Recently, several groups reported that polyelectrolytic biomacromolecules, such

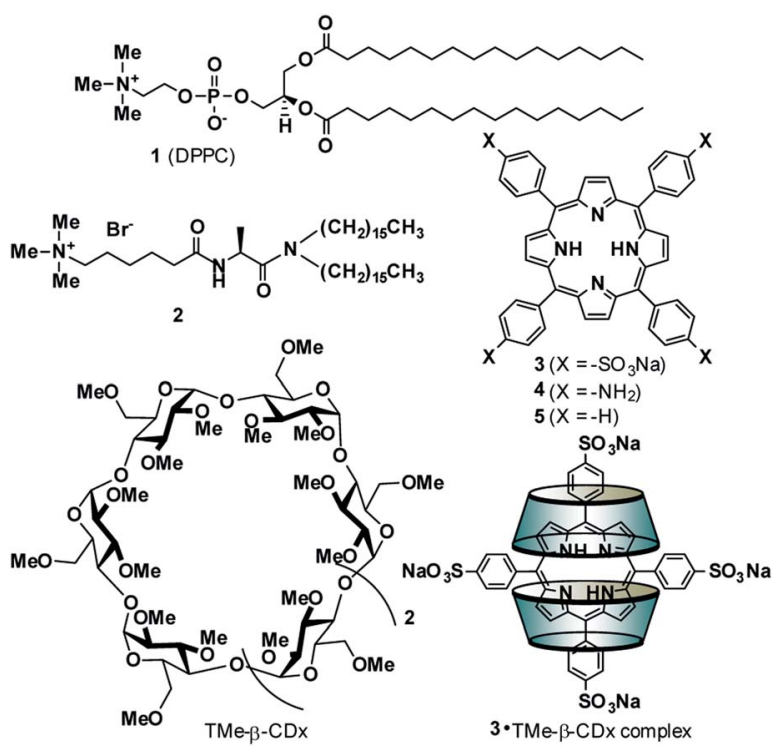

Fig. 1 Compound structures and schematic illustrations of the 3.TMe- $\beta$-CDx complex.

Department of Applied Chemistry, Graduate School of Engineering, Hiroshima University, 1-4-1 Kagamiyama, Higashi-Hiroshima 739-8527, Japan

$\dagger$ Electronic supplementary information (ESI) available: Experimental procedures and UV-vis absorption and ${ }^{1} \mathrm{H}$ NMR spectra. See DOI: 10.1039/c8ra01411f as DNA or nanoparticles with anionic surfaces, were able to adsorb onto liposomal surfaces composed of neutral diacylphosphatidylcholine (PC) $\cdot{ }^{1-12}$ Although the details of the interactions remain unclear, multipoint interactions might exist between the negative charges of these compounds or materials and the positive charge $\mathrm{N}^{+}$of the $\mathrm{P}^{-}-\mathrm{N}^{+}$(phosphorous-nitrogen) dipole of PC. ${ }^{13,14}$ Recently, we showed that 5,10,15,20-tetrakis(4-sulfophenyl)porphyrin (3) (Fig. 1) interacts with the liposomal surface by formation of onedimensional self-assembled structures (J-aggregates) under acidic conditions. ${ }^{15,16}$ In contrast, neutralization of the solution deformed the porphyrin J-aggregates, leading to release of 3 from the liposomal surface. ${ }^{15,16}$ These interactions are important not only for development of novel functional materials by using liposomes, but also for internalization into cells by endocytosis as the first step of intracellular uptake. In this report, 3 was found to interact with liposomal surfaces composed of neutral lipids at high liposome concentrations without the formation of porphyrin J-aggregates (Scheme 1A). Furthermore, 3 was released from the liposomal surfaces by addition of trimethyl- $\beta$-cyclodextrin (TMe- $\beta$-CDx) (Fig. 1, Scheme 1B).

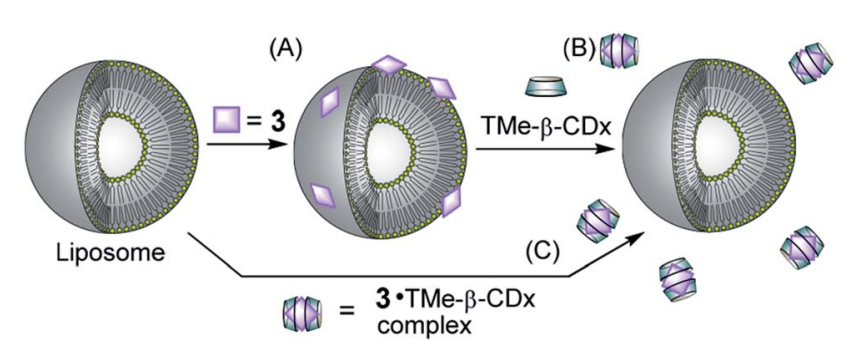

Scheme 1 Schematic illustrations of $(A)$ adsorption of 3 on the liposomal surface, (B) exfoliation of 3 by TMe- $\beta-C D x$ and (C) no interaction between the 3-TMe- $\beta$-CDx complex and a liposome. 

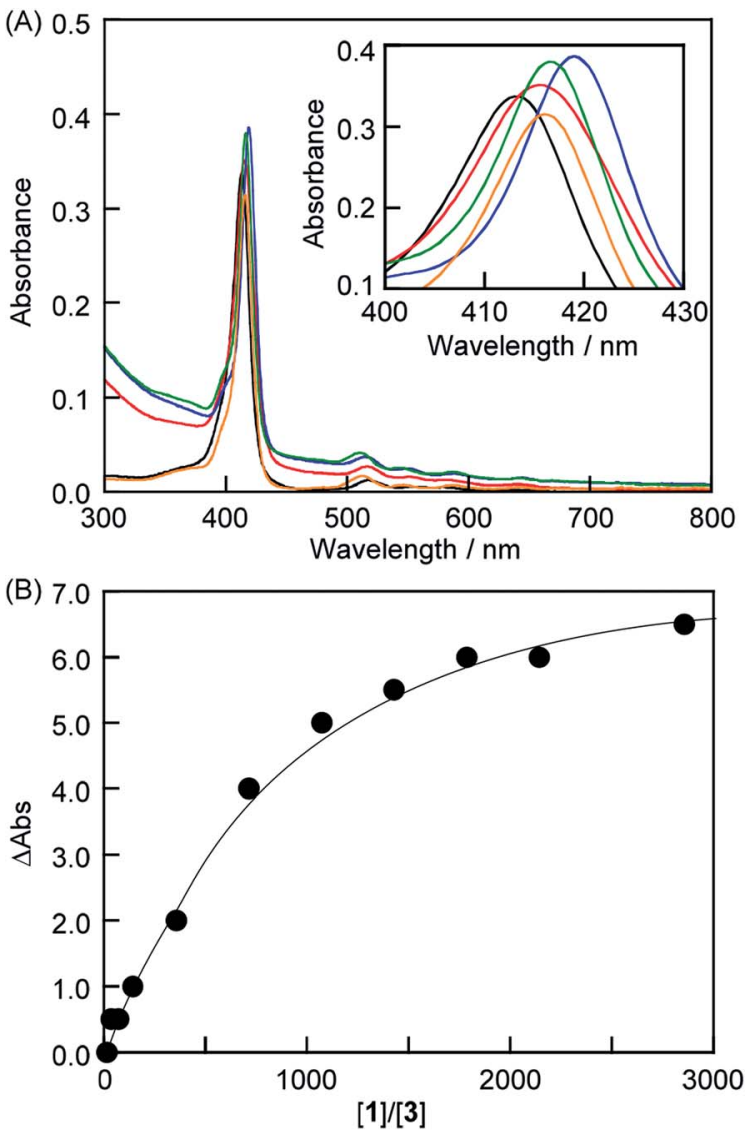

Fig. 2 (A) UV-vis absorption spectra of 3 (black), a mixture of 3 and liposome-1 (red), a mixture of 3 and liposome-1-2 (blue), a mixture of 3, liposome-1 and TMe- $\beta-C D x$ (green), and the 3.TMe- $\beta-C D x$ complex (orange) $\{1 \mathrm{~mm}$ cell, [3] $=7.0 \mu \mathrm{M},[1]=10.0 \mathrm{mM}$ in phosphate buffer $(\mathrm{pH}=6.8)\}$. (B) $\lambda_{\max }$ shift of 3 versus concentrations of 1 at $20^{\circ} \mathrm{C}$ $\{[3]=7.0 \mu \mathrm{M},[1]=0.5-20.0 \mathrm{mM}$ in phosphate buffer $(\mathrm{pH}=6.8)\}$.

\section{Results and discussion}

\section{Interaction between anionic porphyrin and neutral lipid}

The interactions between anionic porphyrin 3 and the neutral lipid 1 [1,2-dipalmitoyl-sn-glycero-3-phosphocholine (DPPC), Fig. 1] were investigated. Concentration dependent UV-vis absorption spectra of $\mathbf{3}$ were measured by the addition of liposomes composed of $\mathbf{1}$ (liposomes-1) (Fig. 2) and the red shift in the Soret band was observed at $20{ }^{\circ} \mathrm{C}(413 \rightarrow 415.5 \mathrm{~nm}, \Delta \mathrm{Abs}=$ $2.5 \mathrm{~nm})$. The red shift was not because of the formation of onedimensional self-assembled structures because: (i) 3 cannot form self-aggregates under neutral conditions because protonation of $\mathbf{3}$ is essential for self-association, and (ii) the shift value is too small for self-aggregates because the Soret band of the porphyrin J-aggregates displayed a significant red shift to $491 \mathrm{~nm} .{ }^{15-18}$ If sulfo groups of 3 interact with ammonio groups of 1 on the liposomal surface, the addition of cationic lipids in the liposome should facilitate the formation of strong interactions between anionic 3 and the liposomal surface via electrostatic interactions. ${ }^{19-21}$ Therefore, a cationic lipid (2) was mixed with lipid 1 in the liposomes $\left\{[1]:[2]=7: 3\left(\mathrm{~mol} \mathrm{~mol}^{-1}\right)\right\}$. As shown in Fig. 2A (blue line), the $\lambda_{\max }$ of $3(419 \mathrm{~nm})$ was red-

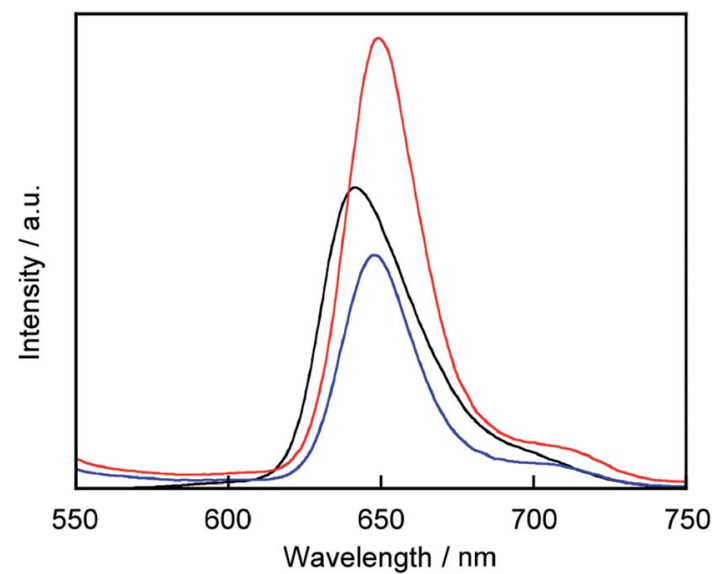

Fig. 3 Fluorescence spectra of 3 (black), a mixture of 3 and liposome1 (red), and a mixture of 3 and $\mathrm{LMIC}_{60}$ (blue). Excitation wavelength: $517 \mathrm{~nm}$. [3] $=0.05 \mathrm{mM},[1]=5.0 \mathrm{mM}$ and $\left[\mathrm{C}_{60}\right]=0.25 \mathrm{mM}$ in phosphate buffer $(\mathrm{pH}=6.8)$.

shifted by $6 \mathrm{~nm}$ when compared with the results obtained by 3 alone in the absence of liposomes [Fig. 2A (black line)]. Therefore, the red shift suggests an interaction between 3 and lipid 1. The shifts of $\Delta \lambda_{\max }$ in the Soret band of 3 were plotted against the concentration of 1 in Fig. 2B. We were not able to determine the association constant between $\mathbf{3}$ and lipid $\mathbf{1}$ from a curve in Fig. 2B. The association constant determined from ${ }^{1} \mathrm{H}$ NMR spectrum is described below. In contrast, we investigated interactions between cationic porphyrin 4 (Fig. 1) and lipid 1. Although the absorbance of $\mathbf{4}$ increased because of the light scattering of liposomes-1, no shift of $\Delta \lambda_{\max }$ in the Soret band of $\mathbf{4}$ was observed (Fig. S1†), indicating that 4 did not interact with the liposomal surface.

\section{Existence of porphyrin on the liposomal surface}

$\mathrm{C}_{60}$ is known to act as a quencher in liposomes. ${ }^{22}$ To confirm that 3 exists on the liposomal surface, we measured fluorescence quenching of 3 by $\mathrm{C}_{60}$ in lipid-membrane-incorporated $\mathrm{C}_{60}\left(\mathrm{LMIC}_{60}\right.$, Fig. 3). The presence of $\mathrm{C}_{60}$ led to a fluorescence quenching of $48 \%$, indicating that 3 exists in the neighborhood of $\mathrm{C}_{60}$.

\section{Form of porphyrin on the liposomal surface}

In the ${ }^{1} \mathrm{H}$ NMR spectra, 3 gives rise to two peaks arising from the phenyl protons in the ortho and meta positions because of the $D_{4 \mathrm{~h}}$ symmetry of 3 (Fig. $4 \mathrm{~A}$ and S2A $\dagger$ ). Although the peak assigned to the phenyl protons in the meta position (8.2 ppm) appeared as a sharp doublet, the corresponding peak for the protons in the ortho position (7.7 ppm) was broader and this line-broadening was ascribed to self-aggregation of $3 .^{23,24}$ In Fig. $4 \mathrm{~B}$, the phenyl protons in the ortho positions of 3 were observed as a pronounced broaden peak (grey circle). ${ }^{23}$ In contrast, when 3 interacted with liposome-1, two pairs of phenyl protons in the ortho and meta positions appeared in a $1: 1$ ratio [Fig. 4B (red circles) and S2B $\dagger$ ]. The result suggests the following three models for the interaction between 1 and 3: $C_{4 \mathrm{v}}, C_{2 \mathrm{v}}$ and $C_{2 \mathrm{v}}$ symmetries, depending on the interaction on the liposomal 


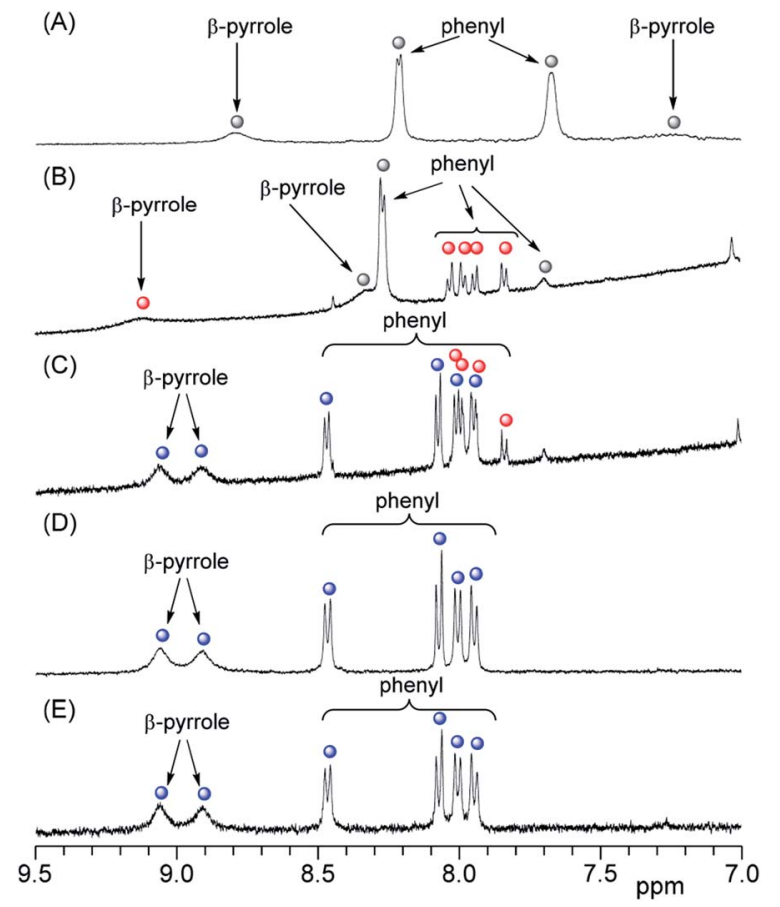

Fig. 4 Partial ${ }^{1} \mathrm{H}$ NMR spectra of $(\mathrm{A}) 3([3]=0.4 \mathrm{mM})$, (B) the mixture of 3 and liposome-1 ([3] $=0.05 \mathrm{mM}$ and $[1]=25 \mathrm{mM})$, (C) the mixture of 3 , liposome-1 and TMe- $\beta$-CDx $([3]=0.05 \mathrm{mM}$, [1] $=25 \mathrm{mM}$ and [TMe- $\beta$ $\mathrm{CDx}]=1.0 \mathrm{mM})$, (D) the $3 \cdot \mathrm{TMe}-\beta-\mathrm{CDx}$ complex $([3 \cdot \mathrm{TMe}-\beta-\mathrm{CDx}$ complex] $=0.40 \mathrm{mM}$ ) and $(\mathrm{E})$ the mixture of the $3 \cdot \mathrm{TMe}-\beta-\mathrm{CDx}$ complex and liposome-1 ([3-TMe- $\beta$-CDx complex] $=0.20 \mathrm{mM}$ and [1] $=4.0 \mathrm{mM}$ ) in $\mathrm{D}_{2} \mathrm{O}$-phosphate buffer $(\mathrm{pH}=6.8$ ) (0: free 3 ; $0: 3$ on the liposomal surface; 0 : 3 in the 3-TMe- $\beta$-CDx complex).

surface (Scheme 2). In Scheme 2A, 3 interacts with liposomal surfaces by four point interactions. The porphyrin face of 3 is shaped asymmetrical at the upper and lower sides. If the rotation of phenyl units decreases and is slower than the NMR time scale because of steric hindrance by the liposome surface, the two ortho and two meta protons in one phenyl unit are in different chemical environments (see Scheme 2A) and give rise to the four signals in Fig. 4B (red circles). For the other possible models, 3 interacts with the liposomal surface by only two $\mathrm{SO}_{3}{ }^{-}$ in the cis-position with $C_{2 \mathrm{v}}$ (Scheme 2B) or the trans-position with $C_{2 \mathrm{v}}$ (Scheme 2C), in which 3 interacts with the $\mathrm{N}^{+}$of $\mathrm{P}^{-}-\mathrm{N}^{+}$ in liposome-1. Because 3 has different symmetries in the three models, the $\beta$-pyrrole protons should appear as one, four or two sets of peaks in the NMR spectrum for models in Schemes 2A, B and $\mathrm{C}$, respectively. As shown in Fig. 4B (red circle), the $\beta$ pyrrole protons appeared as a single broad peak, suggesting that the model in Scheme $2 \mathrm{~A}$ is correct.

\section{Association constant between anionic porphyrin and neutral lipid}

As shown in Scheme 2A, porphyrin 3 interacted with the liposome surface consisted of lipids 1 through four point interactions. Therefore, the equilibrium is defined as (1):

$$
3+4 \cdot 1 \rightleftharpoons 3-4 \cdot 1
$$

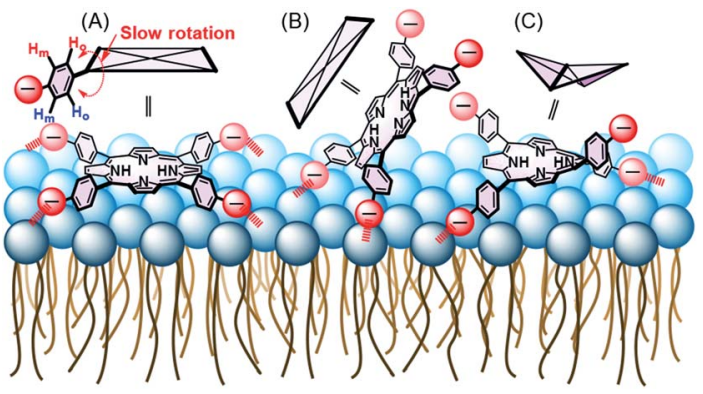

Scheme 2 Schematic illustration of (A) four point interactions between 1 and 3, (B) two point interactions between 1 and the cisposition of 3 and (C) two point interactions between 1 and the transposition of 3 with a saddle-shape structure. Red arrows show the distortion of the lipid membranes and red broken lines show the interactions.

The concentrations of free 3 and 3 on the liposomal surface were determined by the peak intensities in Fig. 4B. When these values were substituted into eqn (2), we obtained the association constant $\left(K_{\mathrm{a}}\right)=9.0 \times 10^{5} \mathrm{M}^{-4}$.

$$
K_{\mathrm{a}}=\frac{\mathbf{3}-4 \cdot \mathbf{1}}{[\mathbf{3}] \cdot[\mathbf{1}]^{4}}
$$

Porphyrin derivatives can form a $1: 2$ complex with TMe- $\beta$ CDx. ${ }^{24-26}$ Furthermore, all of the tetraphenylporphyrin (5) were released from the TMe- $\beta$-CDx cavities and transferred to the lipid membrane after mixing the 5-TMe- $\beta$-CDx complex with liposome-1 at $30{ }^{\circ} \mathrm{C}$ for $1 \mathrm{~h} .{ }^{25}$ Therefore, we attempted the exchange reaction of 3 from TMe- $\beta-C D x$ cavities to lipid membranes or the formation of direct interactions between liposome surfaces and the 3-TMe- $\beta$-CDx complex. After mixing the $3 \cdot$ TMe- $\beta$-CDx complex with liposome-1 under the same conditions reported previously, ${ }^{25}$ all peaks assignable to TMe- $\beta$ CDx in the $3 \cdot$ TMe- $\beta$-CDx complex remained in the ${ }^{1} \mathrm{H}$ NMR spectrum (blue circles in Fig. 4D, E, S2D and E $\dagger$ ). The result shows that porphyrin 3 did not transfer from the TMe- $\beta$-CDx cavities to the liposomes and the porphyrin remained in the TMe- $\beta$-CDx cavities (Scheme 1C). This observation suggests that 3 is too hydrophilic to incorporate into the hydrophobic lipid membrane. Furthermore, no chemical shift changes of these peaks indicate that the $3 \cdot$ TMe- $\beta$-CDx complex did not interact with the liposome surface by only a single point interaction because of steric hindrance by the two TMe- $\beta$-CDxs. Because $K_{\mathrm{a}}$ for the four point interactions was $9.0 \times 10^{5} \mathrm{M}^{-4}, K_{\mathrm{a}}{ }^{\prime}$ per a single point interaction was estimated to be approximately 30 $\mathbf{M}^{-1}$ at most even if entropy and enthalpy gains by multi point interactions were excluded. Therefore, the 3-TMe- $\beta$-CDx complex cannot interact with the liposome surface by only a single point interaction. Consequently, the interactions between 3 and $\mathbf{1}$ need at least four point interactions.

\section{Exfoliation of porphyrin from the liposome surface by cyclodextrin}

To control the association-dissociation of 3 onto the liposomal surface, TMe- $\beta$-CDx was added to the mixture of 3 and 
liposome-1. After adding TMe- $\beta$-CDx, although the $\lambda_{\max }$ of the Soret band of 3 is barely shifted (i.e., 415 to $416 \mathrm{~nm}$ ), the $\lambda_{\max }$ in the Q-band of 3 is shifted from 517 to $511 \mathrm{~nm}$. These $\lambda_{\max }$ were the same as that observed for the $3 \cdot$ TMe- $\beta$-CDx complex ( 416 and $511 \mathrm{~nm}$ ) (Fig. 2A, green and orange). Furthermore, peaks were observed in the ${ }^{1} \mathrm{H}$ NMR spectrum for the $3 \cdot$ TMe- $\beta$-CDx complex (Fig. 4C and $\mathrm{S} 2 \mathrm{C} \dagger$ ). The results show that most of 3 peeled off the liposomal surface and had formed a complex with two TMe- $\beta$-CDxs (Scheme 1B).

\section{Conclusions}

In summary, anionic 3 was adsorbed onto liposomal surfaces composed of neutral lipid $\mathbf{1}$ at high lipid concentrations. The interaction of 3 with 1 was via four contact points. In contrast, the $3 \cdot$ TMe- $\beta$-CDx complex cannot be adsorbed onto liposomal surfaces because 3 interacts with 1 by only a single point and is encapsulated by two TMe- $\beta$-CDxs. Addition of TMe- $\beta$-CDx caused the release of $\mathbf{3}$ from the liposomal surface and complex formation with two TMe- $\beta$-CDxs. Consequently, the association-dissociation of $\mathbf{3}$ onto the liposomal surfaces can be controlled by the addition of TMe- $\beta$-CDx.

\section{Experimental}

\section{Experimental materials}

Trimethyl- $\beta$-cyclodextrin (TMe- $\beta$-CDx) and 5,10,15,20-tetrakis(4sulfophenyl)porphyrin (3) were purchased from Wako Pure Chemical Industries Ltd (Tokyo, Japan) and Tokyo Chemical Industries Co., Ltd (Tokyo, Japan), respectively. 1,2-Dimyristoylsn-glycero-3-phosphocholine (DMPC, 1) was obtained from Funakoshi Co., Ltd (Tokyo, Japan). Compound 2 was prepared according to the method described previously. ${ }^{27}$

\section{Phosphate buffer}

A phosphate buffer was prepared by dissolving a mixture of $\mathrm{NaH}_{2} \mathrm{PO}_{4} \cdot 2 \mathrm{H}_{2} \mathrm{O} \quad(390 \mathrm{mg}, 2.50 \mathrm{mmol}), \quad \mathrm{Na}_{2} \mathrm{HPO}_{4} \cdot 12 \mathrm{H}_{2} \mathrm{O}$ $(181 \mathrm{mg}, 0.50 \mathrm{mmol})$ and $\mathrm{K}_{2} \mathrm{SO}_{4}(1.70 \mathrm{mg}, 9.74 \mathrm{mmol})$ in pure water or $\mathrm{D}_{2} \mathrm{O}(100 \mathrm{~mL})$, to reach a final $\mathrm{pH}$ of 6.5 at $23{ }^{\circ} \mathrm{C}$.

\section{Preparation of liposome-1 and liposome-1-2}

An appropriate amount of 1 or a mixture of 1 and 2 ([1] : [2] = $7: 3 \mathrm{~mol} \mathrm{~mol}^{-1}$ ) was dissolved in chloroform. The solvent was evaporated under a gentle stream of nitrogen, followed by a period under vacuum to remove any traces of solvent. The resulting thin lipid films were hydrated on the wall of the vial above the phase transition temperature with an appropriate amount of phosphate buffer. The hydrated materials were subjected to eight freeze-thaw cycles $\left(-195\right.$ and $\left.50{ }^{\circ} \mathrm{C}\right)$ to give unilamellar vesicles, which were extruded 11 times through 0.05 $\mu \mathrm{m}$ pores using a LiposoFast miniextruder from Avestin (Ottawa, Canada) above the phase transition temperature. The resulting liposomes were uniform in size with a diameter of approximately $80 \mathrm{~nm}$. The final lipid concentration was $3.0 \mathrm{mM}$.

\section{Preparation of the $3 \cdot$ TMe- $\beta$-CDx complex}

Compound 3 (5.00 mg, $\left.5.26 \times 10^{-6} \mathrm{~mol}\right)$ and TMe- $\beta$-CDx $\left(15.0 \mathrm{mg}, 1.05 \times 10^{-5} \mathrm{~mol}\right)$ were placed in an agate capsule with two agate-mixing balls. The resulting mixture was agitated vigorously at $30 \mathrm{~Hz}$ for $20 \mathrm{~min}$ using a high-speed vibration mill (MM 200; Retsch Co., Ltd., Haan, Germany). The solid mixture was suspended in either phosphate buffer or $\mathrm{D}_{2} \mathrm{O}$-phosphate buffer $(1.5 \mathrm{~mL})$ to produce a dark purple emulsion. Subsequent centrifugation $\left(18000 \times g, 25{ }^{\circ} \mathrm{C}, 20 \mathrm{~min}\right)$ removed nondispersed 3 from the solution. The concentration of 3 in the 3-TMe- $\beta$-CDx complex was determined to be $0.03 \mathrm{mM}$ by measuring the absorbance of the solution at $\lambda_{\max }$ in water. The molar absorption coefficient for the water-soluble $3 \cdot$ TMe- $\beta$-CDx complex is $\varepsilon_{416}=3.79 \times 10^{5} \mathrm{dm}^{3} \mathrm{~mol}^{-1} \mathrm{~cm}^{-1}$.

\section{Spectrophotometric assay}

The absorbance spectra were scanned using a UV-2550 spectrophotometer (Shimadzu Corporation, Kyoto, Japan). Fluorescence spectra were obtained using an LS 55 luminescence spectrometer (Perkin-Elmer, Waltham, MA, USA). The excitation and emission wavelengths were 517 and 600-750 nm, respectively.

\section{Conflicts of interest}

There are no conflicts to declare.

\section{Acknowledgements}

This work was supported by a JSPS KAKENHI Grant-in-Aid for Scientific Research (B) (Grant No. JP16H04133) and a Grant-inAid for Challenging Exploratory Research (Grant No. JP16K13982). We thank the Edanz Group (http:// www.edanzediting.com/ac) for editing a draft of this manuscript.

\section{Notes and references}

1 I. A. Khalil, K. Kogure, H. Akita and H. Harashima, Pharmacol. Rev., 2006, 58, 32-45.

2 F. Zhao, Y. Zhao, Y. Liu, X. Chang, C. Chen and Y. Zhao, Small, 2011, 7, 1322-1337.

3 L. Y. T. Chou, K. Ming and W. C. W. Chan, Chem. Soc. Rev., 2011, 40, 233-245.

4 T. M. Allen and P. R. Cullis, Science, 2004, 303, 1818-1822.

5 S. Mayor and R. E. Pagano, Nat. Rev. Mol. Cell Biol., 2007, 8, 603-612.

6 A. Das, R. Thakur and A. Chakraborty, RSC Adv., 2013, 3, 19572-19581.

7 F. Quemeneur, M. Rinaudo, G. Maret and B. Pepin-Donat, Soft Matter, 2010, 6, 4471-4481.

8 P. Karam, A. A. Hariri, C. F. Calver, X. Zhao, K. S. Schanze and G. Cosa, Langmuir, 2014, 30, 10704-10711.

9 L. Zhang and S. Granick, Nano Lett., 2006, 6, 694-698.

10 R. Michel, T. Plostica, L. Abezgauz, D. Danino and M. Gradzielski, Soft Matter, 2013, 9, 4167-4177. 
11 F. Wang, D. E. Curry and J. Liu, Langmuir, 2015, 31, 1327113274.

12 K. Sugikawa, T. Kadota, K. Yasuhara and A. Ikeda, Angew. Chem., Int. Ed., 2016, 55, 4059-4063.

13 C. Adhikari, A. Das and A. Chakraborty, ChemPhysChem, 2015, 16, 866-871.

14 T. Cha, A. Guo and X.-Y. Zhu, Biophys. J., 2006, 90, 12701274.

15 K. Sugikawa, Y. Takamatsu, K. Yasuhara and A. Ikeda, Langmuir, 2017, 33, 1023-1029.

16 K. Sugikawa, Y. Takamatsu, T. Kakigi, K. Yasuhara and A. Ikeda, Chem. Commun., 2017, 53, 10140-10143.

17 O. Ohno, Y. Kaizu and H. Kobayashi, J. Chem. Phys., 1993, 99, 4128-4139.

18 D. L. Akins, H. Zhu and C. Guo, J. Phys. Chem., 1994, 98, 3612-3618.

19 E. Goormaghtigh, J. Caspers and J. M. Ruysschaert, J. Colloid Interface Sci., 1981, 80, 163-170.
20 Z. Wang, K. Yasuhara, H. Ito, M. Mukai and J. Kikuchi, Chem. Lett., 2010, 39, 54-55.

21 K. Hall, T.-H. Lee and M.-I. Aguilar, J. Mol. Recognit., 2011, 24, 108-118.

22 A. Ikeda, T. Sue, M. Akiyama, K. Fujioka, T. Shigematsu, Y. Doi, J. Kikuchi, T. Konishi and R. Nakajima, Org. Lett., 2008, 10, 4077-4080.

23 A. Corsini and O. Herrmann, Talanta, 1986, 33, 335-339.

24 K. Kano, R. Nishiyabu, T. Asada and Y. Kuroda, J. Am. Chem. Soc., 2002, 124, 9937-9944.

25 A. Ikeda, S. Hino, T. Mae, Y. Tsuchiya, K. Sugikawa, M. Tsukamoto, K. Yasuhara, H. Shigeto, H. Funabashi, A. Kuroda and M. Akiyama, $R S C$ Adv., 2015, 5, 105279105287.

26 Y. Tsuchiya, T. Shiraki, T. Matsumoto, K. Sugikawa, K. Sada, A. Yamano and S. Shinkai, Chem.-Eur. J., 2012, 18, 456-465. 27 Y. Murakami, A. Nakano and H. Ikeda, J. Org. Chem., 1982, 47, 2137-2144. 